\title{
Analisis Wacana Terhadap Berita Radio Republik Indonesia Kupang pada Acara Warta Berita Daerah Pagi
}

\author{
Juan Ardiles Nafie \\ Mahasiswa Program Studi Magister Ilmu Komunikasi FISIP UNDIP Angkatan VI \\ Email: Perfect juan@yahoo.com
}

\begin{abstract}
:
Title of this appointed by the background thinking tends to assume the news radio is the boring, stiff and monotonous and thus author shall select said that the news visible life easier understood listeners and the said right of news. Thus the formula problem in this is how the language used in writing of news Radio Republic Indonesia Kupang on a news areas morning. This watchfulness aims to detect radio language that used in Kupang Republic of Indonesia radionews writing, in region news report programme morning.

this watchfulness uses to approach qualitative with a view to get description about language in Kupang Republic of Indonesia Radionews writing in region news report programme morning. data collecting technique that used recording, interview, and documentation

Research results that news news still use the word wasteful or not use the sentence brief congested and said there are still doble said a word, there is a foreign language not included meaning, there are error of writing the name of informant, principle of usage punctuation frequently used in writing the news radio not wear
\end{abstract}

Keywords: News, Language, Radio

\section{Pendahuluan}

Media massa kini tidak bisa lagi dipisahkan dari kehidupan manusia karena media massa, baik cetak maupun elektronik sudah menjadi kebutuhan hidup. Dari kota hingga pedesaan, masyarakat memanfaatkan media massa untuk berbagai keperluan, sesuai dengan fungsi pers, yakni memberikan informasi, memberikan pendidikan, memberikan hiburan, melakukan kontrol sosial.

Media massa merupakan institusi yang berperan sebagai agent of change, yaitu sebagai institusi pelopor perubahan. Sebagai agent of change, media massa juga menjadi institusi budaya, yaitu institusi yang setiap saat menjadi corong kebudayaan, katalisator perkembangan budaya. Radio merupakan salah satu media massa elektronik, salah satu kelebihan radio dibandingkan dengan media lainya ialah cepat dan mudah dibawa ke mana-mana. Radio bisa dinikmati sambil mengerjakan pekerjaan lain, seperti memasak, menulis, menjahit dan semacamnya (Bungin, 2006: 85-86).

Radio Republik Indonesia (RRI) Kupang merupakan salah satu instansi penyiaran di Provinsi Nusa Tenggara Timur untuk menyelenggarakan berbagai informasi dan berita bagi masyarakat yang ada di sekitar wilayah NTT. Radio lebih mengandalkan suara, sehingga bahasa radio harus mampu mengangkat imajinasi pendengar untuk masuk ke dalam berita tersebut atau bisa turut benarbenar merasakan peristiwa yang sedang terjadi atau yang telah terjadi. Peneliti memilih RRI Kupang sebagai lokasi penelitian karena RRI Kupang mulai mengudara sejak tahun 1958 dengan siaran musik, hiburan dan informasi. Sampai dengan pertengahan tahun 1980-an RRI Kupang menjadi satu-satunya media informasi didaerah ini sedangkan radio swasta baru muncul di akhir tahun 1980-an sehingga sampai saat ini Brand Image RRI Kupang masih cukup kuat dan melekat dalam benak masyarakat 
kota Kupang. Acara warta berita daerah pagi merupakan program acara berita pertama disiarkan RRI Kupang tiap harinya Pukul 06:30 WITA dimana pendengar cenderung mencari dan mendengar informasi yang terbaru di pagi hari. Pedoman bahasa jurnakistik, berita yang ditulis harus ringkas, jelas, tertib dan patuh pada aturan atau norma yang berlaku dalam menulis berita, dan juga menarik. Bahasa radio yang digunakan RRI Kupang yang sudah disiarkan terdapat pendobelan kata atau menggunakan kata mubazir, kesalahan membaca naskah, kesalahan menempatkan tanda baca yang membuat pendengar binggung maksud dari berita yang disiarkan. Alasan itulah yang mendorong peneliti untuk melakukan Analisis Bahasa dalam Berita Radio Republik Indonesia Kupang pada Acara Warta Berita Daerah Pagi.

Masalah dalam penelitian ini dapat dirumuskan sebagai berikut : Bagaimana Bahasa Radio yang digunakan dalam penulisan berita Radio Republik Indonesia Kupang, pada acara warta berita daerah pagi ?

Berdasarkan pernyataan masalah di atas, yang menjadi batasan masalah dalam penelitian ini adalah bahasa radio yang digunakan dalam penulisan berita Radio Republik Indonesia Kupang, pada acara warta berita daerah pagi bulan Agustus 2012.
Dari rumusan masalah yang telah dikemukakan di atas maka tujuan dari penelitian ini adalah untuk mengetahui bahasa radio yang digunakan dalam penulisan berita Radio Republik Indonesia Kupang, pada acara warta berita daerah pagi.

\section{Kajian Teoritik}

\section{Teori wacana Teun A.Van Dijk}

Model analisis wacana yang berkembang dan diperkenalkan oleh para ahli di antaranya adalah teori Van Dijk yang paling sering digunakan. Van Dijk mengelaborasi elemenelemen wacana yang bisa diaplikasikan secara praktis.

Van Dijk melihat suatu wacana terdiri atas berbagai struktur/tingkatan, yang masingmasing bagian saling mendukung dan membaginya menjadi tiga tingkatan:

a) Struktur makro merupakan makna global/ umum suatu teks yang dapat dipahami dengan melihat topik dari suatu teks.

b) Superstruktur adalah kerangka suatu teks. Bagaimana struktur dan elemen wacana itu disusun dalam suatu teks secara utuh.

c) Struktur mikro adalah makna wacana yang dapat diamati dengan menganalisis kata, kalimat, proposisi, anak kalimat yang dipakai dan sebagainya.

\section{Tabel 1. Elemen Wacana Van Dijks}

\begin{tabular}{|c|c|c|}
\hline Struktur Wacana & Hal yang Diamati & Elemen \\
\hline Struktur Makro & $\begin{array}{c}\text { TEMATIK } \\
\text { (Apa yang dikatakan?) }\end{array}$ & Topik \\
\hline Superstruktur & $\begin{array}{c}\text { SKEMATIK } \\
\text { (Bagaimana pendapat disusun dan dirangkai?) }\end{array}$ & Skema \\
\hline Struktur Mikro & $\begin{array}{c}\text { SEMANTIK } \\
\text { (Makna yang ingin ditekankan dalam teks berita) }\end{array}$ & $\begin{array}{l}\text { Latar,detail, maksud, } \\
\text { peranggapan, nominalisasi }\end{array}$ \\
\hline Struktur Mikro & $\begin{array}{c}\text { SINTAKSIS } \\
\text { (Bagaimana pendapat disampaikan?) }\end{array}$ & $\begin{array}{l}\text { Bentuk kalimat, } \\
\text { koherensi, kata ganti }\end{array}$ \\
\hline Struktur Mikro & $\begin{array}{c}\text { STILISTIK } \\
\text { (Pilihan kata apa yang dipakai?) }\end{array}$ & Leksikon \\
\hline Struktur Mikro & $\begin{array}{c}\text { RESTORIS } \\
\text { (Bagaimana dan dengan cara apa penekanan } \\
\text { dilakukan?) }\end{array}$ & Grafis, Metafora, Ekspresi \\
\hline
\end{tabular}


Dalam pandangan Van Dijk, segala teks bisa dianalisis dengan menggunakan elemen tersebut. Meski terdiri atas berbagai elemen, namun semua elemen itu merupakan suatu kesatuan, saling berhubungan dan mendukung satu sama lainnya. Untuk memperoleh gambaran ihwal elemen-elemen struktur wacana tersebut, berikut akan dijelaskan singkat tentang elemen tersebut (Sobur, 2009:74).

\section{Batasan Konsep}

\section{Pedoman Bahasa Jurnalistik}

1. Ringkas, hematkata denganmenghilangkan bagian yang tidak penting.

2. Jelas, mudah dimengerti dan tidak mengundang pembaca untuk bertanyatanya dan membingungkan.

3. Tertib dan patuh pada aturan atau norma yang berlaku dalam menulis berita; pengunaan bahasa, susunan kata, prioritas dan sebagainya.

4. Singkat, harus memperhatikan titik, koma dan tanda baca lain. Membaca berita tentu tidak sama dengan mambaca buku, untuk itu berita harus berisi kalimat yang singkat agar mudah dipahami pembaca.

5. Menarik, menulis berita yang menarik sangat penting menjadi tugas wartawan yang ditentukan oleh kemampuanya menulis (Djuraid, 2009 : 140-141)

\section{Menulis Naskah Radio}

Menyampaikan dan menulis berita elektronik, secara prinsip, tetap mengunakan $5 \mathrm{~W}+1 \mathrm{H}$, tetapi Romli (2004) dalam Mondry mengemukakan beberapa perbedaan, antara lain sebagai berikut.

1. Bahasa Tutur

Kalimat harus menggunakan bahasa tutur ( spoken language atau conventional language ) berupa bahasa percakapan sehari-hari dan informal.

2. Sederhana dan Singkat

Gunakan kata-kata sederhana dan singkat.
Kalimat panjang tentu menyulitkan penyiar dan sulit dicerna pendengar atau pemirsa. Apalagi bila pendengar tidak mendengarkan kalimat secara lengkap, bisa jadi salah persepsi.

3. Enak didengar

Dalam menyiarkan berita, usahakan kalimatnya enak didengar dan mudah dimengerti. Prinsipnya, sekali diucapakan, pendengar atau pemirsa bisa langsung paham, jangan menimbulkan tanda tanya atau mereka harus mengerutkan kening memikirkan makna tersebut.

4. Hindari Singkatan

Dalam menyampaikan informasi atau berita, jangan mengunakan singkatan, kecuali yang sudah diketahui masyarakat kerena bisa beragam makna yang ditangkap pendengar.

\section{Logis}

Berdasarkan menyusun kalimat dengan SPOK ( subjek, predikat, objek dan keterangan, jangan terbalik-balik). Uraikan intinya, lalu jelaskan.

6. Permudah

Permudah pendengar dengan menyampaikan inti masalah, tidak perlu rinci, misalnya nomor surat keputusan tidak diperlukan. Bulatkan angka yang mungkin membingungkan pendengar.

7. Sign-posting

Gunakan tanda baca (punctuation) dalam kalimat, guna membantu mempermudah penyiar membaca berita tersebut. Biasanya, tanda garis miring (/) pengganti tanda koma, tanda garis miring dua $(/ /)$ pengganti tanda titik. Dan tanda garis miring tiga $(/ / /)$ penanda akhir naskah. (Mondry, 2008 : 176)

\section{Metoda Penelitian}

Penelitian ini merupakan penelitian deskriptif dengan pendekatan penelitian kualitatif yang mencari tahu atau menjelaskan 
hubungan, tidak menguji hipotesis atau membuat prediksi. Model penelitian yang digunakan dalam penelitian ini adalah analisis wacana teks. Penelitian ini dilakukan pada Lembaga Penyiaran Publik Radio Republik Indonesia Kupang yang berlokasi di Jalan. Tompello No.8, Kota Kupang, Nusa Tenggara Timur. Alasan peneliti memilih RRI Kupang karena RRI Kupang menjadi radio yang pertama muncul di daerah ini. Waktu yang digunakan untuk penelitian ini ialah bulan Agustus 2012. Dalam penelitian ini yang menjadi Objek penelitian ialah bahasa radio dalam berita Radio Republik Indonesia Kupang. Unit analisis penelitian ini dalah naskah berita Radio Republik Indonesia Kupang. Dalam menentukan unit analisis dalam penelitian ini, penulis memilih 6 topik berita pada bulan Agustus 2012. Sumber dan Jenis Data

a. Data primer adalah data yang diperoleh peneliti secara langsung di lapangan berupa naskah berita.

b. Data sekunder dapat berupa hasil wawancara, dokumen, buku-buku referensi yang diperlukan untuk menunjang data primer yang ada kaitannya dengan penulisan ini.

Dalam setiap penelitian, teknik pengumpulan data sangat penting karena menentukan berhasil atau tidaknya suatu penelitian. Kesalahan penggunaan teknik pengumpulan data akan berakibat fatal terhadap hasil penelitian. Karena itu untuk memperlancar dan menunjang tercapainya tujuan penelitian ini maka penulis menggunakan teknik pengumpulan data sebagai berikut : (1)Rekaman. Peneliti menggunakan teknik pengumpulan data berupa rekaman berita-berita yang disiarkan guna sebagai bahan penunjang dalam penelitian. (2)Wawancara. Teknik ini merupakan proses memperoleh keterangan untuk tujuan penelitian yakni tanya jawab antara peneliti dengan penulis naskah berita dengan mengunakan panduan yang telah disiapkan untuk masalah yang akan diteliti. (3) Dokumentasi. Catatan peristiwa yang sudah berlalu. Dokumen dalam hal ini berupa naskah berita yang digunakan untuk dibacakan dalam penyiaran berita.
Teknik analisis data yang digunakan adalah analisis isi. Data yang akan dianalisis dalam penelitian ini berupa naskah berita yang menjadi unit pengamatan penelitian, data rekaman dan hasil wawancara. Dengan demikian untuk menganalisis data dalam penelitian menempuh langkah-langkah sebagai berikut: (a)Triangulasi. Dalam tahap ini, peneliti mengabungkan teknik pengumpulan data yakni rekaman dan naskah berita untuk menganalisis data-data yang diperoleh oleh peneliti. (b) Reduksi Data. Reduksi data merupakan proses pemilihan, pemusatan perhatian, pengabstraksian dan pentransformasikan data kasar di lapangan. Proses ini berlangsung selama penelitian dilakukan, dari awal sampai akhir penelitian. (c) Penyajian Data, Penyajian data adalah sekumpulan informasi tersusun yang memberi kemungkinan untuk menarik kesimpulan dan pengambilan tindakan. Bentuk penyajiannya berupa teks naratif, matriks, grafik, jaringan, dan bagan. Yang paling sering digunakan untuk menyajikan data dalam penelitian kualitatif adalah dengan teks yang bersifat naratif. Tujuannya untuk memudahkan membaca dan menarik kesimpulan. (d) Verifikasi Data. Peneliti membuat rumusan proposisi yang terkait dengan prinsip logika, mengangkatnya sebagai temuan penelitian, kemudian dilanjutkan dengan mengkaji secara berulang-ulang terhadap data yang ada, pengelompokkan data yang telah terbentuk, dan proposisi yang telah dirumuskan. Langkah selanjutnya yaitu melaporkan hasil penelitian lengkap, dengan temuan baru yang berbeda dengan temuan yang ada.

\section{Hasil Penelitian}

Berita yang disiarkan RRI Kupang selalu berpatokan pada naskah yang sudah disiapkan sebelumnya sehingga apa yang disampaikan dalam program acara berita sesuai dengan naskah yang disiapkan.

Naskah berita RRI Kupang terdapat pengunaan bahasa media cetak, kata-kata mubazir, pendobelan kata yang seharusnya tidak perlu dicantumkan dalam berita tersebut. Selain itu, penggunaan tanda baca seperti tanda koma dan titik yang tidak tepat sehingga dapat 
meyulitkan pembaca dalam membaca berita. Prinsip penggunaan tanda baca yang biasanya dalam naskah media elektronik tanda garis miring (/) pengganti tanda koma, tanda garis miring dua (//) pengganti tanda titik, dan tanda garis miring tiga $(/ / /)$ penanda akhir naskah, tidak digunakan. Naskah berita RRI Kupang menggunakan tanda baca koma (,) dan hanya mengunakan tanda garis miring tiga $(/ / /)$.

\section{Pembahasan}

\section{Analisis Naskah Berita Edisi Rabu, 1 Agustus} 2012

Salah satu berita pagi 1 Agustus 2012 berjudul "Penyambutan Peserta Sail Morotai 2012 dan Launching Sail Komodo 2012”.

Secara teknis kebahasaan, penulisan berita ditemukan beberapa kesalahan. Ditemukan bentuk boros atau mubazir seperti kutipan dibawah ini:

“...Gubernur juga mengajak dan mempersilahkan para peserta sail morotai untuk menikmati berbagai objek wisata yang ada di NTT// bahkan gubernur meminta untuk para peserta sail agar dapat menceritakan tentang kekayaan budaya dan objek wisata yang ada di NTT di negaranya masingmasing//"

Pada paragraf di atas banyak kata mubazir (bentuk boros) yang seharusnya tidak perlu. Bentuk boros tersebut terdapat kata "para peserta". Salah satu kata di atas dihilangkan, dan dapat ditulis dengan peserta, kata "untuk", "tentang" bisa dihilangkan, kata "yang ada di" bisa dihilangkan. Demikian pula, "di NTT", seharusnya digantikan dengan "NTT" karena kalimat sesudahnya sudah menggunakan "di" sehingga tidak terjadi pendobelan agar penggunaan kalimat lebih singkat dan jelas.

\section{Struktur Tematik}

Segi Tematik berita di atas mengangkat topik dengan judul "Penyambutan Peserta Sail Morotai 2012 dan Launching Sail Komodo 2012".Berita berjudul "Penyambutan Peserta Sail Morotai 2012 dan Launching Sail Komodo 2012" menjelaskan mengenai dua peristiwa yakni penyambutan peserta Sail Morotai 2012 dan Launching sail Komodo 2013.

\section{Struktur Skematik}

Penulisan lead pada berita "Penyambutan Peserta Sail Morotai 2012 dan Launching Sail Komodo 2012”, lebih menjelaskan pada penyambutan Sail Morotai 2012. Kesempatan itu gubernur NTT menyampaikan selamat datang kepada 405 orang peserta sail dari 17 negara yang tiba di Kota Kupang.

Skema yang dibentuk dan dijelaskan dalam penulisan berita di atas ialah : Gubernur NTT meyampaikan selamat datang kepada 405 orang peserta sail dari 17 negara, Gubernur mengajak dan mempersilahkan para peserta sail morotai untuk menikmati objek wisata di NTT, Gubernur meminta para peserta menceritakan tentang kekayaan budaya dan objek wisata di NTT, Gubernur berharap melalui kegiatan NTT Ekspo dapat mendorong usaha kerajinan guna meningkatkan pendapatan masyarakat, Gubernur meminta dukungan dan peran aktif dari semua Pemerintah Daerah di NTT.

\section{Struktur Semantik}

Makna yang ingin ditekankan dalam berita di atas ialah gubernur berharap kekayaan budaya dan objek wisata NTT dapat dikenal manca negara, dan dengan adanya NTT Ekspo dapat meningkatkan pendapatan masyarakat serta dukungan dari semua pemerintah daerah.

\section{Struktur Sintaksis}

Segi sintaksis, penulisan berita "Penyambutan Peserta Sail Morotai 2012 dan Launching Sail Komodo 2012" menggunakan kalimat yang berstruktur aktif, dimana seseorang menjadi subjek dari pernyataannya.

\section{"Gubernur NTT Frans Leburaya atas nama Pemerintah dan masyarakat NTT menyampaikan selamat datang kepada 405 orang peserta sail dari 17 negara yang telah tiba di kota kupang NTT sebagai entri point pertama dari Sail Morotai 2012”}


Bagian dari berita di atas menunjukkan bahwa dalam penulisan berita dengan topik "Penyambutan Peserta Sail Morotai 2012 dan Launching Sail Komodo 2012” menggunakan kalimat yang berstruktur aktif.

\section{Struktur Stilistik}

Pusat perhatian stilistik adalah pada style, . Dalam konteks ini, style dapat diterjemahkan sebagai gaya bahasa. Gubernur NTT Frans Leburaya atas nama Pemerintah dan masyarakat merupakan gaya bahasa pars prototo artinya sebagian mewakili keseluruhan. Kalimat tersebut menjelaskan gubernur mewakili pemerintah dan seluruh masyarakat NTT.

Penulisan berita di atas masih menggunakan istilah asing "entri point", Penulisan tidak disertai artinya dimana Pendengar tidak semua pahan tentang istilah itu, sehingga perlu dihindari pengunaan istilah asing.

\section{Struktur Retoris}

Segi retoris, tidak banyak elemen retoris yang digunakan untuk penonjolan teks. Hanya dalam teks berita di atas terdapat penggunaan tanda baca yang menggunkan tanda garis miring tiga (///) sebagai pengatur intonasi pembaca berita dalam membaca berita yang disiarkan.

\section{Analisis Naskah Berita Edisi Kamis, 2 Agus- tus 2012}

Warta berita pagi menyajikan berbagai berita diantaranya berita yang berjudul " 1 hari pasca pelantikan walikota baru, Sekda Kota Kupang jalani vonis di pengadilan tipikor".

Pengunaan kata pada berita tidak mengunakan bahasa tutur, seperti kata "Pasca" bisa ditulis dengan "setelah". Penulisan kejadian baru terjadi sehari sebelumnya, seperti pada naskah berita di atas : "rabu 1 Agustus 2012" dapat ditulis dengan hari rabu tanggal 1 Agustus kemarin.

“...sesusai rencana hari ini 2 agustus 2012 pengadilan tipikor kupang menggelar sidang terakhir pembacaan putusan terhadapdugaan kasuskorupsi 6 unit kapal ikan di dinas kelautan dan perikanan (DKP) kota kupang tahun 2009//I yang menyeret nama sekda kota kupang di era pemerintahan DANIEL ADOE, yakni sekda kota kupang HABDE ADRIANUS DAMI sebagai terdakwa///"

Penggunaan boros (kata) dijumpai pada kata kalimat di atas, dimana radio yang bersifat selintas dengar dan terbatas oleh waktu karena itu sebaiknya ditulis singkat, padat dan jelas, yakni : "yang menyeret nama Sekda Kota Kupang di era pemerintahan DANIEL ADOE, yakni sekda kota kupang HABDE ADRIANUS DAMI sebagai terdakwa///" kalimat tersebut terjadi pendobelan penulisan "Sekda Kota Kupang”. Pemborosan kata itu bisa ditulis dengan "menyeret Sekda Kota Kupang HABDE ADRIANUS DAMI sebagai terdakwa///".

\section{Analisis Naskah Berita Edisi Sabtu, 4 Agus- tus 2012}

Tanggal 4 Agustus 2012, RRI Kupang menyajikan salah satu berita berjudul "Program di pengadilan tidak akan di rubah".

Pada penulisan berita setelah penulisan jabatan seharusnya ditulis nama dari orang tersebut. Seperti : "Ketua Pengadilan Tinggi Kupang ANDARIAS K. PERUASAN yang baru dilantik menggantikan A. TH. PUDJIWAHONO kepada R-R-I di Kupang mengatakan....". Penulisan berita seperti itu dapat membangun persepsi pendengar yang berbeda-beda, ketika pendengar mendengarkan "Ketua Pengadilan Tinggi Kupang yang baru dilantik ANDARIAS K. PERUASAN menggantikan Ketua Pengadilan Tinggi Kupang yang lama A.TH.PUDJIWAHONO kepada RRI di Kupang mengatakan tidak akan meubah sistim kerja yang selama ini berjalan di pengadilan" pendengar bisa salah paham dan beranggapan bahwa Ketua Pengadilan Tinggi Kupang yang baru dilantik oleh ANDARIAS K. PERUASAN menggantikan A.TH.PUDJIWAHONO. Meskipun dalam 
penulisan berita di atas tidak mencantumkan kata "oleh" tapi dengan menulisnya seperti itu dapat membangun persepsi masyarakat yang berbeda sehingga dalam penulisan jabatan atau kedudukan seseorang harus disusul oleh nama orang tersebut.

“...A.TH.PUDJIWAHONO kepada RRI di kupang mengatakan tidak akan merubah sistim kerja yang selama ini berjalan di pengadilan//I ditegaskan dirinya datang bukan untuk merobak sistim yang ada, apa yang telah diprogramkan oleh ketua pengadilan yang lama akan terus di lanjutkan //I yang jelas harus berpacu pada blue print tugas pokok di keluarkan oleh mahkamah agung/// jika tidak tidak bisa di pertahankan lagi maka maka akan ada perubahan///"

"Sementara menyinggung tentang ketersediaan tenaga hakim di provinsi NTT ketua pengadilan tinggi kupang ANDARIAS K PERUASAN mengatakan saat ini di NTT belum ada penambahan tenaga hakim/// hakim yang ada

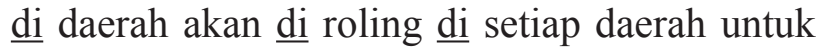
menjamin idependensi hokum dan keadilan///".

Selain itu, bagian berita di atas terlalu banyak menggunakan "di" dan "yang" sehingga tidak enak didengar. Sesuai dengan prinsip penulisan berita radio yang singkat, padat dan jelas juga enak didengar maka perlu menghindari pendobelan kata yang membuat pendengar merasa jenuh.

Pendobelan kata masih juga terjadi pada kalimat “...selain itu KPT ANDARIAS PERUASAN juga memberikan rencana pembentukan 3 pengadilan negeri yang akan di bentuk di 3 kabupaten dalam waktu dekat yakni di kabupaten Nagekeo, Sumba Barat Daya dan Manggarai Timur///". Seharusnya "yang akan di bentuk" bisa dihilangkan karena sebelum sudah ditulis "rencana pembentukan" sehinnga kalimat selanjutnya tidak perlu ditulis "yang akan di bentuk" agar kalimat tersebut lebih singkat, padat, jelas, enak didengar dan tidak membosankan.

\section{Analisis Naskah Berita Edisi Senin, 6 Agus- tus 2012}

Tanggal 6 Agustus 2012, RRI Kupang menyajikan salah satu berita berjudul "kegiatan sertifikasi barang dan jasa".

Awal kalimat paragraf menggunakan kata "untuk". Dalam kaidah penulisan mengawali kalimat dengan kata "untuk" tidak tepat sehingga tidak enak didengar, yakni : "Untuk memberikan pemahaman kepada para panitia Pengadaan Barang Jasa, BP4D Provinsi NTT, melalui Bidang Tekhnis Fungsional Bekerja sama dengan LKPP pusat melaksanakan kegiatan DIKLAT Sertifikasi Barang dan Jasa". Sebaiknya ditulis "BP4D Provinsi NTT, Melalui Bidang Tekhnis Fungsional bekerja sama dengan LKPP pusat melaksanakan Kegiatan DIKLAT Sertifikasi Barang dan Jasa untuk memberikan Pemahaman kepada Para Panitia Pengadaan Barang Jasa”.

Selain itu, penulisan nama orang dalam berita di atas tidak konsisten. Bagian awal berita, nama kepala Bidang Tekhnis Fungsional ditulis BERNADET USBOKO, pertengahan berita ditulis ERNI USBOKO, dan bagian akhir berita ditulis BERNNADETA USBOKO.

Ketidakkonsisten dapat membingungkan pendengar saat mendengarkan berita tersebut dan merugikan bagi orang yang namanya persis dengan salah satu nama yang dibacakan di atas. Hal ini membuat pendengar beranggapan bahwa terdapat tiga orang yang dibicarakan dalam berita tersebut. Menulis nama narasumber perlu ditulis jelas dan sesuai dengan nama asli dari narasumber tersebut.

\section{Analisis Naskah Berita Edisi Selasa, 14 Agus- tus 2012}

Tanggal 14 Agustus 2012, RRI Kupang menyajikan salah satu berita berjudul “ Walikota dan wakil walikota pimpin rapat HUT kemerdekaan RI".

Penulisan berita tidak menngunakan bahasa tutur yakni pada penulisan waktu yang 
dimana masih menuliskan dengan pukul 13 WITA. Seharusnya kata pukul ditulis dengan jam 1 siang. Radio mempunyai ciri selintas dengar tentunya menghindari penjelasan secara rinci pada berita, untuk itu dalam penulisan berita mencantumkan "peninjauan jalan Beringin dikelurahan Sikumana tepatnya di RT 12 RW 5 yang diperbaiki sendiri oleh warga masyarakat". Kalimat tersebut seharusnya ditulis : peninjauan jalan Beringin dikelurahan Sikumana yang diperbaiki sendiri oleh warga masyarakat.

\section{Analisis Naskah Berita Edisi Rabu, 15 Agus- tus 2012}

Tanggal 15 Agustus 2012, RRI Kupang menyajikan salah satu berita berjudul "Paripurna pelantikan antar waktu DPRD Kota Kupang”.

Penulisan berita berjudul "Paripurna pelantikkan antar waktu DPRD Kota Kupang" terdapat pengunaan bahasa media cetak atau tidak mengunakan bahasa tutur, yakni : "Paripurna Pelantikan Antar Waktu tersebut, di rencanakan akan dilaksanakan pada Rabu, 15 Agustus 2012, Pukul 11.00 WITA bertempat di Ruang Sidang Utama DPRD Kota Kupang”. Kalimat tersebut mencanatumkan tanggal dimana berita itu disiarkan pada tanggal itu juga, jadi bisa ditulis dengan "hari ini", selanjutnya ditulis pada naskah "pukul 11.00 WITA", pada penulisan berita radio seharusnya pukul 11.00 WITA diganti dengan jam 11 siang.

\section{Penutup}

\section{Kesimpulan}

Pencermatan terhadap Bahasa Berita Radio Repulik Indonesia Kupang pada Acara Warta Berita Pagi, peneliti dapat menyimpulkan hal-hal sebagai berikut:

1. Penulisan naskah berita pada Radio Repulik Indonesia Kupang masih menggunkan kata-kata mubazir atau tidak menggunakan kalimat yang singkat, padat dan jelas, tidak mengunakan bahasa tutur, masih ada pendobelan kata-kata.

2. Pengunaan gaya bahasa dalam Radio
Repulik Indonesia Kupang masih terdapat bahasa asing yang tidak disertakan artinya, sehingga membuat pendengar tidak paham maksud dari berita yang disiarkan.

3. Berita Radio Repulik Indonesia Kupang terdapat kesalahan penulisan nama narasuber. Penulisan nama narasumber tidak konsisten membuat pembaca dan pendengar tidak paham atas berita yang disiarkan.

4. Prinsip penggunaan tanda baca yang sering digunakan dalam penulisan berita radio yakni, tanda koma (,) diganti dengan tanda garis miring satu (/), tanda titik (.) diganti dengan tanda garis miring dua (//), tanda berakhir suatu berita ditandai dengan tanda titik (.) tidak dipakai dalam penulisan berita RRI Kupang pada acara warta berita daerah pagi dan masih menggunakan tanda titik (.) dan tanda koma (,) dalam naskah berita.

\section{Saran}

Sebaiknya perlu kerja sama yang baik dalam news room antara penulis naskah dan pembaca berita. Sebelum berita diturunkan, perlu dilakukan editing baik oleh pembaca berita/ newscaster maupun oleh editor berita.

Di samping itu dalam penulisan naskah berita radio perlu menggunakan kalimat yang singkat, padat dan jelas, mengunakan bahasa tutur agar pendengar dapat memahami isi berita dengan baik. Penggunaan tanda baca sesuai prinsip penulisan media elektronik (radio) sebaiknya digunakan agar mempermudah penyiar dalam membaca berita yang disiarkan.

\section{DAFTAR PUSTAKA \\ BUKU}

Anwar, H. Rosihan. (2004). Bahasa jurnalistik Indonesia \& Komposisi, Yogyakarta

:Media Abadi.

Bakhtiar, Amsal. (2005). Filsafat Ilmu. Jakarta: Rajawali Pers

Basrowi dan Suwandi. (2008). Memahami 
Penelitian Kualitatif, Jakarta: Rineka Cipta.

Bungin, H.M. Burhan. (2008). Konstruksi Sosial Media Massa”, Jakarta: Kencana.

$$
\text { . (2006). Sosiologi }
$$

Komunikasi, Jakarta: Kencana.

Cangara, H. Hafied. (2007). Pengantar Ilmu Komunikasi, Jakarta: PT Raja Grafindo Persada.

Djuraid, Husnun N. (2009). Panduan Menulis Berita, Malang: UMM Press.

Effendi, Onong Uchjana. (1993). Ilmu, Teori dan Filsafat Komunikasi, Bandung: Citra Aditya Bakti.

Eriyanto. (2001). Analisis Wacana: Pengantar Analisis Teks Media. Yogyakarta: LKIS.

Haryatmoko. (2007). Etika Komunikasi. Yogyakarta: Kanisius.

Mondry. (2008). Pemahaman Teori dan Praktik Jurnalistik, Bogor: Ghalia Indonesia.

Muhammad, Farouk. (2004). Praktik Ilmu Komunikasi dalam Kehidupan SehariHari. Jakarta Selatan: Teraju.

Narwaya, Tri Guntur. (2006). Matinya Ilmu Komunikasi, Yogyakarta: Resist Book.

Nurudin. (2009). Jurnalisme masa kini. Jakarta; Rajawali Pers. , (2007). Pengantar Komunikasi Massa. Jakarta: PT. Raja Grafindo Persada.

Romli. Asep Syamsul M. (2004). Broadcast Jurnalism. Bandung: Nuansa.
Sobur Alex. (2009). Analisis Teks Media. Bandung: PT Remaja Rosdakarya.

Sugiyono. (2009). Metode penelitian kuantitatif kualitatif dan R\&D, Bandung:

Alfabeta.

Sumadiria, AS Haris. (2008). Jurnalistik Indonesia. Bandung: PT Remaja Rosdakarya Offset.

Yosef, Jani. (2008). To Be A Journalist :Menjadi Jurnalis TV, Radio dan Surat Kabar yang Propesional, Yogyakarta : Graha Ilmu

\section{INTERNET}

http://classyfm.co.id/blog/caveen/ uncategorized/105/ akses tanggal 30/05/2012 pukul 20:30 WITA.

http://rahman-azzam.blogspot.com/2007/05/ wacana-theon-lvan-dijk.html akses tanggal 10/04/2012 pukul 09: 53 WITA. http://pojokspy.blogspot.com/2008/06/ membuat-naskah-berita-radio-yang.

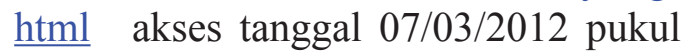
$09: 24$ WITA.

http://classyfm.co.id/blog/caveen/ uncategorized/105/ akses tanggal 07/03/2012 pukul 09:18 WITA.

http://media.kompasiana.com/mainstreammedia/2011/08/24/menulis-untukradio-menghadirkan-theatre-of-mind/ akses tanggal 07/03/2012 pukul 09:33 WITA. 